\title{
SMEDDS TABLET: COMPATABILITY OF SOLID SMEDDS USING VARIOUS PHARMACEUTICAL TABLET EXCIPIENTS
}

\author{
NASER M. Y. HASAN*, DHAIFALLAH M. ALMALKI, MOHAMMED J. K. ALTHUWAYBI AND HASSAN M. ALSHEHRI \\ School of Pharmacy, Taif University, Saudi Arabia \\ Email: n.hasan@tu.edu.sa
}

Received: 10 Jun 2016 Revised and Accepted: 22 Jul 2016

\section{ABSTRACT}

Objective: There are many successful products on the market which are the culmination of the self-micro-emulsification lipid technology applications. Despite the importance of lipid-based formulations, these systems have some limitations including; stability, complexity during large scale manufacturing process and limited dosage forms to such as soft gelatin capsule. In order to overcome these limitations, the prospect of converting self-micro-emulsifying drug delivery systems (SMEDDS) into tablet dosage form was investigated in this study.

Methods: A self-micro-emulsifying oil formulation representing type III A lipid class composed of glycerox $767 \mathrm{HC} / \mathrm{croduret} 40$ ss at ratios of (80/20) was converted into solid SMEDDS using solid carrier adsorption method. Powder blends containing magnesium trisilicate hydrate (MTSH) or magnesium lluminum silicate (MAS) at various oil loading factors were mixed with MCC with and without various binders and compressed into tablets using a fixed loading force of approximately of $5 \mathrm{KN}$. Hardness profiles of these oil loaded tablets were then analyzed.

Results: Powder compacts which contained MTSH with and without SMEDDS oil had shown relatively better compaction properties than MAS. Adding SMEDDS oil solution to either MTSH or MAS at ratios of 1:9 has relatively reduced tablets hardness by almost 2 or 4 folds, respectively.

Conclusion: Progressive inclusion of increasing amounts of SMEDDS oil solution adsorbed unto the solid carrier has incurred a further reduction in the hardness of SMEDDS tablets. It appears that manufacturing of tablet SMEDDS can only be attainable for highly potent drugs as minimal amounts of oil solution added to the powder blends can adversely affect the mechanical strength of compressed tablet.

Keywords: SMEDDS, S-SMEDDS, Tablet SMEDDS, Magnesium Aluminum Silicate, Magnesium Trisilicate hydrate

(C) 2016 The Authors. Published by Innovare Academic Sciences Pvt Ltd. This is an open access article under the CC BY license (http://creativecommons. org/licenses/by/4. 0/) DOI: http://dx.doi.org/10.22159/ijpps.2016v8i9.13409

\section{INTRODUCTION}

Self-emulsifying drug delivery systems (SEDDS) and Self-microemulsifying drug delivery systems (SMEDDS) in recent years have received much attention to improve bioavailability of hydrophobic drug specially, almost $40 \%$ of new APIs exhibit poor aqueous solubility [1-3]. This has galvanized pharmaceutical research and industry and hence, many successful products using lipid-based technology were introduced to the market including; Neoral ${ }^{\circledR}$ (Cyclsoprin A, Novartis) [4], Kaletra ${ }^{\circledR}$ (Lopinavir and Ritonavir, Abbott) [5], Rocaltrol ${ }^{\circledR}$ (Calcitriol, Roche) [6] and Avodart ${ }^{\circledR}$ (Dutasteride, GlaxoSmithKline) [7].

SEDDS or SMEDDS is described as mixtures of oil and surfactant which emulsify in water under condition of gentle agitation producing $\mathrm{o} / \mathrm{w}$ fine dispersions of particle size of either $<5 \mu \mathrm{m}[8]$ or between 5 to $150 \mathrm{~nm}$ [9], respectively. In order to facilitate formulation design of lipid systems, they were classified by Pouton [10] into type I, II and III and IV according to the hydrophilicity of oil mixture, oil droplet size after aqueous dispersion and digestion by bile salts. One advantage which, both SEDDS and SMEDDS have over solid dosage formulations is, the avoidance of slow and incomplete drug dissolution as they can facilitate the formation of solubilised phases from which absorption may occur $[11,12]$.

Nonetheless, formulation design of self-emulsifying lipid technology has some disadvantages including; possible interaction between the filling and the capsule shell, precipitation of either active ingredient and/or oil constituents as influenced by storage temperature, besides high manufacturing cost $[13,14]$. To overcome these problems, solid SMEDDSs have been investigated as alternatives which may have the advantages of low production cost, convenience of process control, high stability and reproducibility with better patient compliance [15]. There are many available techniques that can be used to convert conventional liquid SMEDDS to solid (SSMEDDS). This includes: (A) spray drying or freeze drying; in this method, oil formulation is mixed with a solid carrier such as aerosil
200 [16] or dextran [17] in a suitable solvent. The solvent is then gets evaporated forming dry particles under a controlled temperature and airflow conditions [15, 18, 19, 20]. (B) adsorption to solid carriers; the Liquid SEDDS or SMEDDS can be made to adsorb onto free flowing powders that possess very large surface area and are capable of adsorbing high quantities of oil material. Solid adsorbents which are used include: silicates, magnesium trisilicate, talcum, crospovidone, cross-linked sodium carboxymethyl cellulose and cross-linked polymethyl methacrylate, microporous calcium silicate (Florite RE), magnesium aluminometa silicate (Neusilin US2) and silicon dioxide (Sylysia 320), and maltodextrin $[21,-25]$. (C) solid dispersion; in this method, drug is dissolved in the lipid solution and physically mixed with suitable polymer, the mixture is heated until the fluid state is reached and then the melt is cooled [14]. Among the popular carriers used in the formulation of solid dispersions are polyethylene glycols (PEG) polyvinylpyrrolidone (PVP), hydroxyl propyl methylcellulose (HPMC)) [26], sugars, polyacrylates and urea. (D) extrusion spheronization; in this method, the Liquid SEDDS is first mixed with a binder such as MCC, followed by addition of water until the mass is suitable for extrusion. The extruded mass is then spheronized to form uniform sized pellets [27, 28]. (E) melt granulation; in this method; oil formulation is mixed with a binder such as Gelucire ${ }^{\circledR}$ that softens at relatively low temperature which then can be granulated [29]. The field of solid SMEDDS is extensively reported in literature using various drugs including; clopidogrel napadisilate [30], gentamicin [22], heparin [21], carbamazepine [31], cyclosporine-A [32], sirolimus [33] and dutasteride [34]. The original Rapamune ${ }^{\circledR}$ (sirolimus, an immunosuppressant agent) by Pfizer (formerly by Wyeth) is an oral oil based formulation which required refrigerated storage and needs dilution in water or juice before administration. On the other hand, the tablet formulation of sirolimus was launched in 2002 using NanoCrystal ${ }^{\circledR}$ technology acquired by Elan Corporation (Dublin, Ireland) [35]. This formulation however requires special production facilities, and the production of nanoparticles consumes large amounts of energy. 
Furthermore, its bioavailability is even lower than the original oral oil based dosage form $(<17 \%)$ [36]. Nanocrystals are particles made by we-milling a drug, water and a stabilizer which can reach a size up to $400 \mathrm{~nm}$. Nonetheless, there is no single tablet SEDDS or SMEDDS product commercially available on the market that uses the common identified solid self-emulsifying technology discussed earlier. This raises various formulation design concerns with regards to solid SEDDS or SMEDDS some of which are; stability of oil in the solid matrix due to possible lipid migration to the surface which might induce drug crystallization, reliability and feasibility of the pharmaceutical large scale production of these systems, loading capacity of the drug in the amorphous state, compressibility of these systems when considering tablet dosage forms and the compromising of bioavailabity, as solid self-emulsifying systems have to undergo disintegration and dissolution processes before absorption can take place. In this investigation, an oil SMEDD formulation representing type III B lipid class system was converted into solid SMEDDS using adsorption solid carrier method. The effect of lipid concentration, type and concentration of adsorbent carrier and various tablet excipients on the compressibility profile of the developed solid SMEDDS was studied in an attempt to produce tablet SMEDDS with high drug loading capacity and optimum physical characteristics and structural integrity.

\section{MATERIALS AND METHODS}

\section{Materials}

Crodamol GTCC (medium chain triglyceride), glycerox 767HC (PEG 6 caprylic/capric glycerides and croduret 40ss (PEG 40 Hydrogenated Castor Oil) were all supplied by Croda as gift samples. Magnesium aluminum silicate, magnesium trisilicate hydrate, hydroxyl propyl methyl cellulose, gum tragacanth, sodium starch glycolate and alginic acid were supplied by Himedia, India. Microcrystalline cellulose $50 \mu \mathrm{m}$ grade was purchased from Organics. Soluble starch was obtained from Scharlaua and silica gel from Fluka.

\section{Self-Emulsification profiles of lipid mixtures}

According to the method developed by Hasan et al., [11, 12], blends of various oils, co-surfactants and surfactants were accurately weighed into glass test tubes and then wrapped by cling film. Test tubes were heated in a water bath at $50{ }^{\circ} \mathrm{C}$ for 2 min before lipid mixtures were thoroughly vortexed. Lipid formulations were equilibrate over night in an oven set up at $25^{\circ} \mathrm{C}$. Emulsions were prepared under conditions of gentle agitation at a controlled temperature of $37^{\circ} \mathrm{C}$. An amount of $1 \mathrm{~g}$ of each lipid mixture was introduced into $100 \mathrm{ml}$ of distilled water in a $500-\mathrm{ml}$ glass beaker and gentlly agitatated for $15 \mathrm{~min}$ at a controlled temperature of $37^{\circ} \mathrm{C}$. Resulting emulsions were assessed visually and systems which produced clear micro-emulsions were identified as SMEDDS.

\section{Measuring bulk and tapped densities}

Bulk and tapped densities were measured on a $50 \mathrm{ml}$ sample of various powders in a $100 \mathrm{ml}$ measuring cylinder. The measuring cylinder was tapped 500 to 1000 times using tab density tester (Tap-25 Logan Instruments Corp).

\section{Preparation of tablet SMEDDS}

Oil system was prepared by mixing glycerox 767HC (PEG 6 caprylic/capric glycerides and croduret 40ss (PEG 40 Hydrogenated Castor Oil) at ratios of 8:2. Liquid oil solution was mixed with either magnesium aluminum silicate (MAS) or magnesium trisilicate hydrate (MTSH) at oil loading factors of $\{1: 9\},\{2: 8\}$ and $\{3: 7\}$. Oil adsorbed solid carriers was then admixed with microcrystalline cellulose with and without other binder excipients. The powder mixture was compressed into tablets on Erweka single punch tableting machine (EP-1 vers-2), using Adamus (01/12 16X8 mm) punch and a fixed loading force of approximately $5 \mathrm{KN}$. Tablet thickness was measured using (Micrometer, MandW. Ltd, Sheffild; England).

\section{Measuring tablet hardness}

Tablet hardness was determined on tablets compressed at $1.5 \mathrm{~m}$ ton for 3 seconds on Erweka GmbH tablet hardness machine (TBH 225, Germany).

\section{RESULTS AND DISCUSSION}

\section{Self-micro-emulsifying lipid system}

In order to maximize the bioavailability of lipophilic drugs, key elements in the lipid composite have to be optimized which include; type of oil (LCT or MCT), oil-cosurfactant ratio and type of surfactant (HLB value) [11, 37]. Fig. 1 shows the emulsification profile of a lipid system composed of crodamol GTCC (oil), glycerox 767HC (cosurfactant) and croduret 40 ss (non-ionic surfactant). This system is thoroughly investigated by our group in various studies to improve oral bioavailability of Curcumin [12] and as a recipient o/w microemulsion to mask the unpleasant taste of drugs [38]. Hence, a self-micro-emulsifying lipid system that is composed of glycerox $767 \mathrm{HC} /$ croduret 40 ss at ratios of $(8 / 2)$ (see arrow depicted on fig. 1) was selected as a basis to be converted into solid SMEDDS using solid carrier adsorption method. This oil system is expected to have, from one hand, high solubilization capacity to the drug due to the high content of polar mono-and di-medium-chain (C8-C10) triglycerides and moreover, low viscosity.

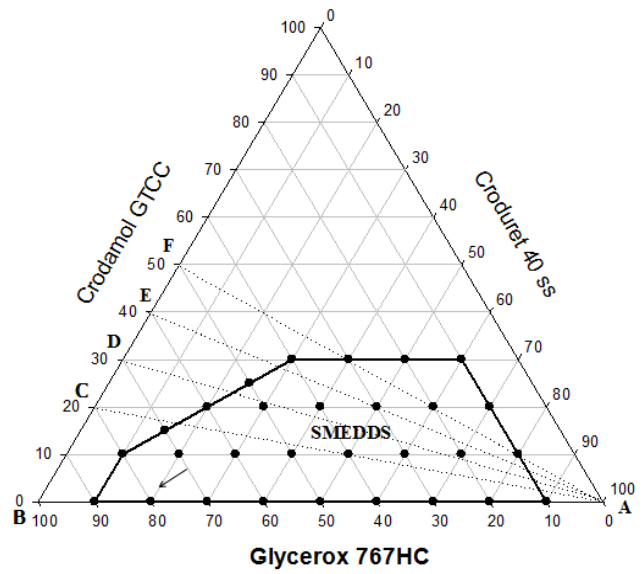

Fig. 1: Emulsification profile of a lipid system composed of crodamol GTCC (oil), glycerox 767HC (co-surfactant) and croduret 40 ss (non-ionic surfactant)

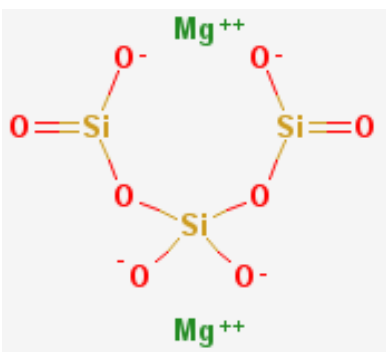

(a)

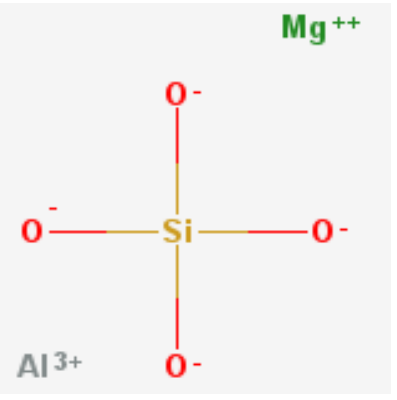

(b)

Fig. 2: Chemical structures of the solid adsorbent carriers (a) magnesium trisilicate hydrate (MTSH) and (b) magnesium aluminum silicate (MAS) 


\section{Compressibility of carrier systems}

Microcrystalline cellulose (MCC) is one of the most important tableting excipients due to its outstanding dry binding properties, enabling the manufacture of tablets by direct compression (DC) [39]. During compression MCC plastically deforms and therefore maximizes the area of inter-particle bonding [40]. The proximity of hydrogen groups on adjacent cellulose molecules enables the formation of numerous hydrogen bonds, which account almost exclusively for the strength and cohesiveness of compacts, even under low compression forces [41]. Therefore, MCC was chosen in this study as a direct compression excipient; in an attempt to develop self-micro-emulsifying tablet dosage form. Based on previous studies by Hasan et al. [12, 38], a selfmicro-emulsifying oil formulation representing type III A lipid class composed of glycerox $767 \mathrm{HC} /$ croduret 40 ss at ratios of $(80 / 20)$ was selected and converted into solid SMEDDS using solid carrier adsorption method. Magnesium trisilicate hydrate (MTSH) and magnesium aluminum silicate (MAS) were used in this study as solid carriers to adsorb oil solution, see fig. 2 for chemical structures.

MCC alone was compressed using a fixed force of approximately 5 $\mathrm{KN}$ into tablets which have thickness of $(7 \mathrm{~mm})$, weight of $0.5 \pm 0.05 \mathrm{~g}$ and measured hardness values ranging from 80-100 N. MCC was blended with increasing concentrations of either MTSH or MAS and compressed into tablets using the same applied force $(\approx 5 \mathrm{KN})$ with same tablet's dimensions. Hardness profiles of these tablets were measured and depicted in fig. 3. Tablets made from blends of MCC and MTSH have produced hardness values relatively higher than tablets containing only MCC. Moreover, hardness profiles of tablets composed of MCC and MTSH blends have generally produced relatively higher values than MCC blends containing MAS. The progressive inclusion of MTSH up to $30 \% \mathrm{w} / \mathrm{w}$ in MCC blends has not significantly influenced corresponding hardness values of tablets. On the contrary, the inclusion of more MAS in the MCC blends has ensued in dramatic loss of tablet hardness values. Almost, $65 \%$ reduction in the hardness of tablets was observed on adding $30 \%$ $\mathrm{w} / \mathrm{w}$ of MAS to MCC blends. The improved tablets hardness profiles of blends containing MTSH in comparison to MAS can be attributed to the high compact ability of MTSH, probably owing to its relatively high bulk and taped density and furthermore, due to water of hydration present in magnesium trisilicate molecules. The interaction between the solid material and the water can cause changes in the physical structure of the compact and hence, change the bonding characteristics within the tablet and ensue increase in the tablet strength [42]. It is worth mentioning here that, Neusilin ${ }^{\circledR}$ S1 by Fuji Chemical industries which is hydrated MAS has shown good compression behavior when mixed with different grades of MCC according to a study by Zhao et al., [32]. This reflects the fact that the presence of water hydration in either MTRH or MAS is quintessential to the compaction behavior of powder beds when making tablets.

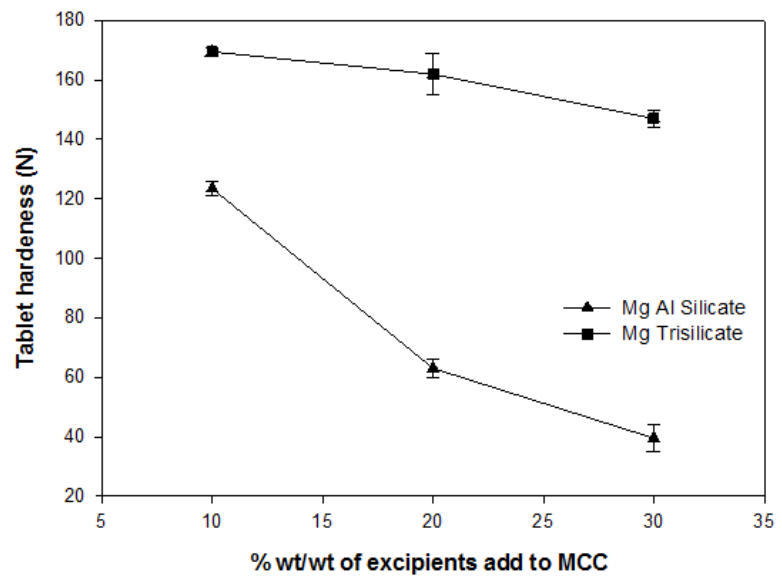

Fig. 3: Hardness profiles of tablets composed of MCC blended with increasing concentrations of either magnesium trisilicate hydrate (MTSH) or magnesium aluminum silicate (MAS)

Powder blends were compressed into tablets using a loading force of $(\approx 5 \mathrm{KN})$. $(\mathrm{n}=3$; data is given in mean $\pm \mathrm{SD})$

\section{Compressibility of solid SMEDDS (S-SMEDDS)}

Effect of oil loading factor on the hardness profiles of SMEDDS tablets

Oil loading factor can be identified here as the amount of oil adsorbed unto carrier i.e. ratio of added oil to the adsorbent carrier. Each adsorbent carrier has a maximum oil loading capacity as for example according to the product specification Neusilin ${ }^{\circledR}$ (MAMS) can absorb approximately $3 \mathrm{ml} / \mathrm{g}$ of oil. In the case of choosing hard gelatin capsule as a dosage form to deliver S-SMEDDS, the amount of oil adsorbed unto the solid carrier is not of paramount importance, as long as required doses is obtained and optimum powder flowability is maintained to ensure capsule filling during the manufacturing process. Yet, however, the oil loading factor is crucial in the case producing tablet SMEDDS as the amount of oil adsorbed unto the solid carrier will influence compaction process and hence tablet strength.

Effect of oil loading factor on the hardness of SMEDDS tablets for a self-micro-emulsifying system \{glycerox $767 \mathrm{HC} /$ croduret 40 ss (80/20)\} adsorbed unto MTRH or MAS as solid carriers and blended with MCC is depicted in fig. 4 to 7 . At loading force of approximately $5 \mathrm{KN}$ (30 MPa), MAS mixed with MCC has not shown very good compressibility as discussed earlier. On the other hand, at equivalent amounts of MCC in the binary mix (MCC/MAS), adding SMEDDS oil solution to MAS at ratios of 1:9 has relatively reduced tablets hardness by almost 4 folds in comparison to MCC/MAS blends without any adsorbed oil; see fig. 3 and 4 . Hardness of tablets which are composed of $90 \% \mathrm{w} / \mathrm{w}$ MCC and $10 \% \mathrm{w} / \mathrm{w}$ MAS was around $120 \mathrm{~N}$ (fig. 3) while, blending same amount of MCC with MAS saturated with $2 \% \mathrm{w} / \mathrm{w}$ of oil (i.e. at oil loading factor of 1:9), has sharply decreased tablets hardness to almost only $30 \mathrm{~N}$ (fig. 4). Furthermore, at oil loading factor of 2:8 or 3:7, hardness of tablets was further reduced. At oil loading factor of 3:7 tablets were rendered uncompressible. This is confirmed, however, in the contour plot depicted in fig. 5 , which shows that the progressive inclusion of increasing amounts of oil adsorbed unto the solid carrier, the further the reduction in the hardness of tablets is observed. On the other hand, MTSH has shown very good compressibility when blended with MCC as described earlier in fig. 3. Effect of oil loading factor on the hardness of tablet SMEDDS using MTRH as an oil adsorbent carrier is depicted in fig. 6 and 7.

Almost 2 fold reduction in the tablets hardness is observed when blending $80 \% \mathrm{w} / \mathrm{w}$ MCC with $20 \%$ MTSH containing $2 \% \mathrm{w} / \mathrm{w}$ of oil (oil loading factor of 1:9) in comparison to blends of MCC/MTSH with no adsorbed oil, see fig. 3 and 6. However, this reduction in the hardness of tablets in the case of using MTSH as an oil adsorbent carrier is far less than using MAS. This could be attributed to the fact that MTSHHHH has a relatively higher oil loading capacity than MAS and furthermore, due to the hydrated nature of MTSH which can improve compressibility.

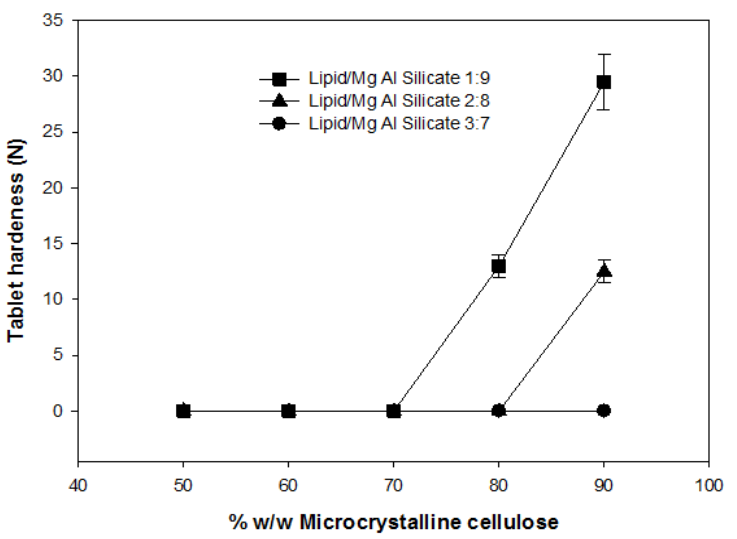

AQ 2

Fig. 4: Effect of oil loading factor on the hardness of tablet SMEDDS tablets composed of self-micro-emulsifying oil solution adsorbed unto MAS solid carriers at ratios of 1:9, 2:8 and 3:7 and blended with increasing concentrations of MCC. ( $n=3$; data is given in mean \pm SD) 
Magnesium trisilicate due to its high surface area of at least 400 $\mathrm{m}^{2} / \mathrm{g}$ which has a flake-like structure having multiple interstitial spaces, contain from about $1 \%$ to about $20 \%$ by weight of the adsorbate of a medicament drug [43].

Moreover, as in the case of using MAS as a solid carrier, the progressive inclusion of increasing amounts of oil adsorbed onto the MTSH has induced a further reduction in the hardness of tablets is observed, see fig. 6 and 7.

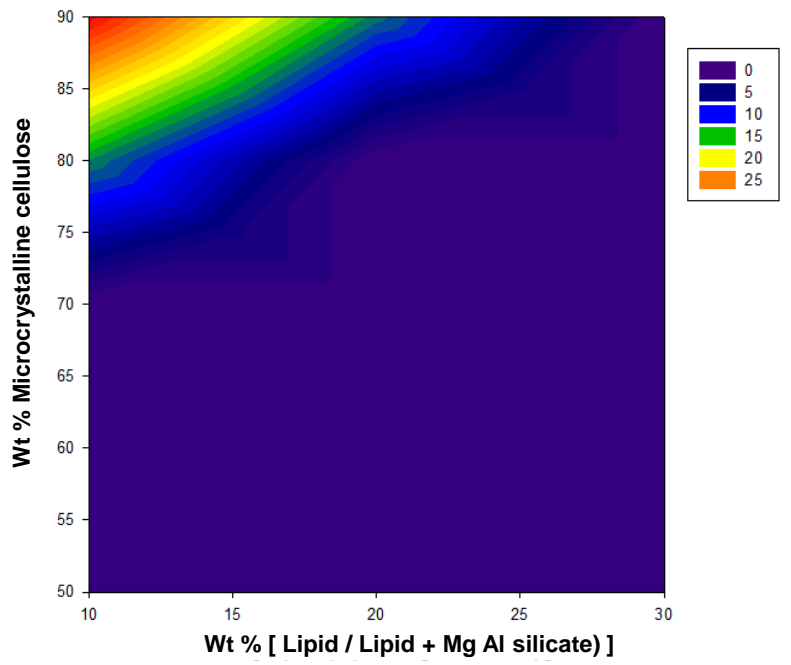

Fig. 5: Contour plot showing the effect of the progressive inclusion of increasing amounts of oil adsorbed onto MAS as the solid carrier on the hardness of tablet SMEDDS

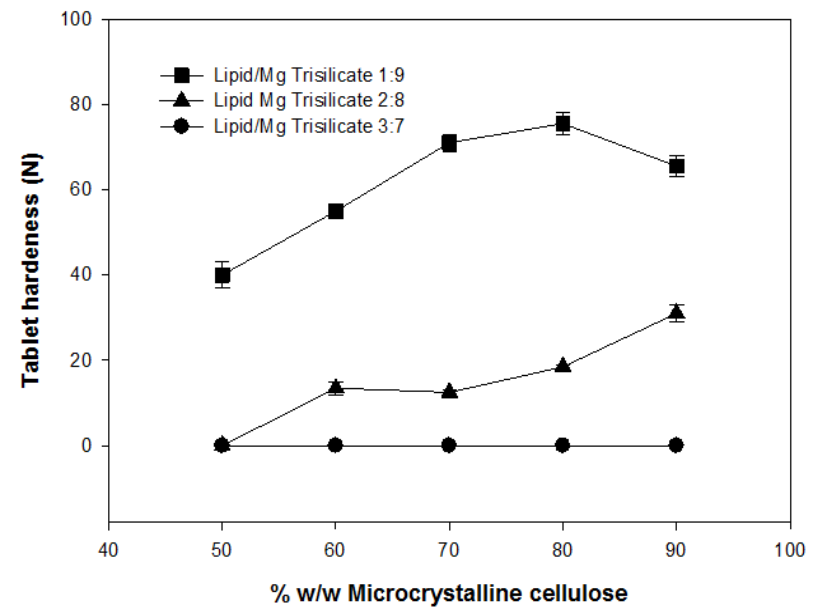

Fig. 6: Effect of oil loading factor on the hardness of tablet SMEDDS tablets composed of self-micro-emulsifying oil solution adsorbed onto MTSH solid carriers at ratios of 1:9, 2:8 and 3:7 and blended with increasing concentrations of MCC. $(n=3$; data is given in mean $\pm \mathrm{SD}$ )

In a study by Sander et al., [44], tablets of porous carrier magnesium alumino- metasilicate (Neusilin US2) was prepared by direct compression method using high loading force (50 MPa) and subsequently loaded with SMEDDS containing Cyclosporine A (CyA) by a simple absorption method.

The bioavailability of CyA from SMEDDS loaded into a disintegrating loadable tablet was found to be at the same level as from capsule formulation. In another study, Self-micro-emulsifying Cyclosporine A tablets were prepared by the liquisolid compaction technique [32] SMEDDS oil mixture at ratio $26.92 \% \mathrm{w} / \mathrm{w}$ containing $25 \mathrm{mg}$ CyA was blended with microcrystalline cellulose (Avicel PH 101 and Avicel $\mathrm{PH}$ 102) as the carrier materials and subsequently mixed with magnesium alumino- metasilicate (Neusilin ${ }^{\circledR} \mathrm{S} 1$ ) as the coating material. This liquid solid compact powder was then compressed into tablets with measured hardness values of around $50 \mathrm{~N}$. It is worth mentioning here that an equivalent vehicle to liquisolid compact powder used in the former study [32] was reproduced in our laboratory and found to be un-compressible at the loading force of $5 \mathrm{KN}$ which is used here in all of our investigations.

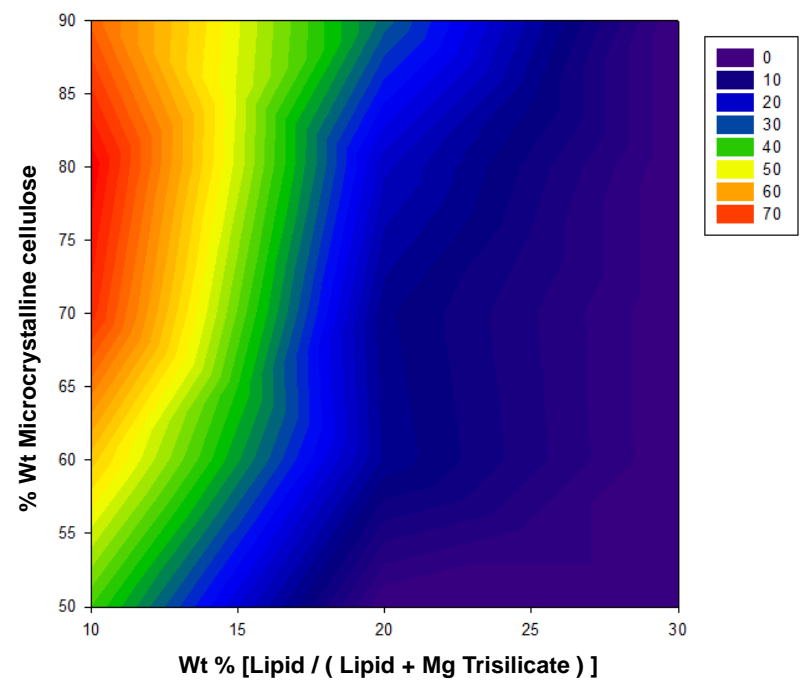

Fig. 7: Contour plot showing the effect of the progressive inclusion of increasing amounts of oil adsorbed onto MTSH as the solid carrier on the hardness of tablet SMEDDS

\section{Effect of binder on the hardness profiles of SMEDDS tablets}

Fig. 8 and 9 show the effect of adding different binders on the hardness of tablets prepared from blends of MCC and solid adsorbent carriers of either MAS or MTSH containing adsorbed amounts of SMEDDS oil solution of 2 or $4 \% \mathrm{w} / \mathrm{w}$. All Filled and clear symbols depicted on fig. 8 and 9 represent blends that contain adsorbed amounts of oil at concentrations of either 2 or $4 \% \mathrm{w} / \mathrm{w}$, respectively. As fig. 8 and 9 suggest, including $4 \mathrm{w} / \mathrm{w} \%$ of oil solution in the blends which contain either MAT (fig. 8) or MTSH (fig. 9) as an adsorbent carriers has comparatively produced lower hardness profiles than corresponding mixtures contain only $2 \% \mathrm{w} / \mathrm{w}$ oil, regardless type and concentration of the added binder.

This suggests that the added binders probably due to hydrophilic nature can't counter act softening effect of oil to the compact powder which reduces the strength of tablets. Amongst blends which contain $2 \%$ or $4 \% \mathrm{w} / \mathrm{w}$ of oil and MAS as an adsorbent carrier, the use of gum tragacanth as a binder has produced relatively higher hardness profiles, see fig. 8 . On the other hand, amongst blends which contain $2 \%$ or $4 \% \mathrm{w} / \mathrm{w}$ of oil and MTSH as an adsorbent carrier, relatively higher hardness profiles was observed in the case of using either gum tragacanth or Silica Gel, respectively, see fig 9. It is worth mentioning here, that in the case of using MAS, capping of compressed tablets was observed in blends which contained silica gel at oil ratio of $4 \%$ $\mathrm{w} / \mathrm{w}$, alginic acid at oil ratios of 2 and $4 \% / \mathrm{w}$, and gum tragacanth at oil ratio of $4 \% \mathrm{w} / \mathrm{w}$. On the other hand, capping was not observed in all blends in which MTSH was used as an adsorbent carrier. 


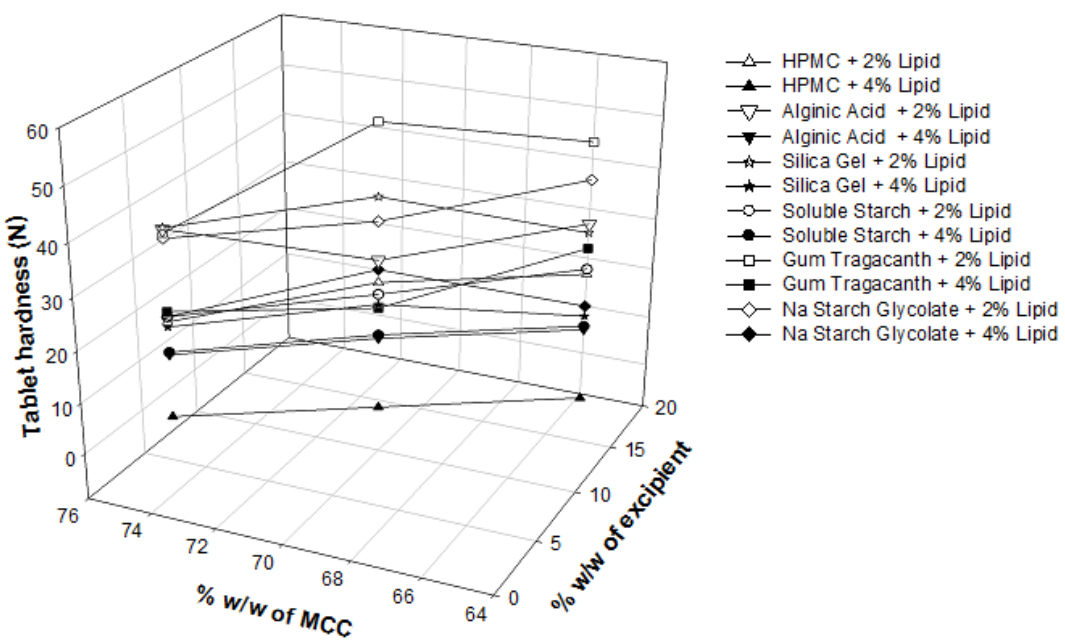

Fig. 8: Effect of various binders on the hardness of SMEDDS tablets prepared from blends of MCC and MAS as solid adsorbent carrier containing adsorbed amounts of SMEDDS oil solution of 2 or $4 \% w / w$

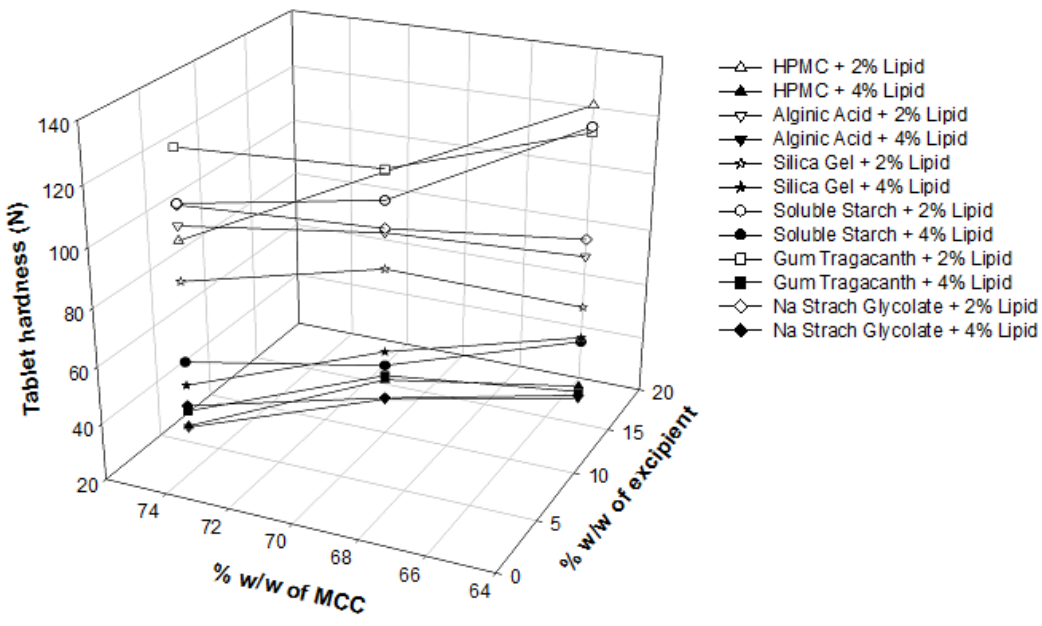

Fig. 9: Effect of various binders on the hardness of SMEDDS tablets prepared from blends of MCC and MATSH as solid adsorbent carrier containing adsorbed amounts of SMEDDS oil solution of 2 or $4 \% \mathrm{w} / \mathrm{w}$

\section{CONCLUSION}

A self-micro-emulsifying oil formulation representing type III A lipid class composed of glycerox $767 \mathrm{HC} /$ croduret 40 ss at ratios of $(80 / 20)$ was selected and converted into solid SMEDDS using MAS or MTSH as solid adsorption carriers and MCC as a binder. Powder compacts which contained MTSH with and without SMEDDS oil had shown relatively better compaction properties than MAS. Adding only 2 to $4 \% \mathrm{w} / \mathrm{w}$ of oil to the powder mix sharply reduces tablet strength. This reduction was found relatively higher in the case of using MAS than MTSH. It appears that manufacturing of tablet SMEDDS is far beyond fulfillment in the foreseeable future due to various reasons. One of which, is the low drug loading capacity due to the limited amount oil containing the dissolved drug which can be added to the powder compact without changing mechanical behavior of the compressed tablet. Therefore, tablet SMEDDS technology can only be developed for highly potent drug such as sirolimus which needs to be administered at 1 or $2 \mathrm{mg}$ dose.

\section{ACKNOWLEDGMENT}

We are grateful to the Faculty of Pharmacy at Taif University for providing a good atmosphere and excellent facilities of research. We are also grateful to Croda Corporation for providing excepients needed as gifts.

\section{CONFLICTS OF INTERESTS}

All authors have none to declare

\section{REFERENCES}

1. Seo YG, Kim DH, Ramasamy T, Kim JH, Marasini N, Oh YK, et al. Development of docetaxel-loaded solid self-nanoemulsifying drug delivery sys-tem (SNEDDS) for enhanced chemotherapeutic effect. Int J Pharm 2013;452:412-20.

2. Woo JS, Song YK, Hong JY, Lim SJ, Kim CK. Reduced food-effect and enhanced bioavailability of a self-micro emulsifying formulation of itraconazole in healthy volunteers. Eur J Pharm Sci 2008;33:159-65.

3. Kyatanwar AU, Jadhav KR, Kadam VJ. Self micro emulsifying drug delivery system (SMEDDS): a review. J Pharm Res 2010;3 Suppl 1:75-83.

4. Murdandea SB, Gumkowskia MJ. Development of a selfemulsifying formulation that reduces the food effect for torcetrapib. Int J Pham 2008;351:15-22.

5. Lugt JVD, Lange J, Avihingsanon A, Ananworanich J, Sealoo S, Burger $\mathrm{D}$, et al. Plasma concentrations of generic lopinavir/ritonavir in HIV type-1infected individuals. Antiviral Ther 2009;14:1001-4.

6. Kubisaa B, Stammbergera U, Guggerb M, Uduehia AN, Grodzkic T, Schmida RA. 1,25-Dihydroxycholecalciferol with low-calcium 
diet reduces acute rejection in rat lung allotransplantation. Eur J Cardio-Thoracic Surgery 2012;11:1-7.

7. Choo GH, Park SJ, Hwang SJ, Kim MS. Formulation and in vivo evaluation of a self-micro emulsifying drug delivery system of dutasteride. Drug Res 2013;63 Suppl 4:203-9.

8. Shah NH, Carvajal MT, Patel CI, Infeld MH, Malick AW. Selfemulsifying drug delivery system (SEDDS) with polyglycolyzed glycerides for improving in vitro dissolution and oral absorption of lipophilic drugs. Int J Pharm 1994;106:15-23.

9. Farah N, De Teddeo M, Larfrêt JP, Denis J. Self micro emulsifying drug delivery system for improving in vitro dissolution of drugs. AAPS Annual Meeting, Orlando, FL; 1993.

10. Pouton CW. Formulation of poorly water-soluble drugs for oral administration: physicochemical and physiological issues and the lipid formulation classification system. Eur J Pharm Sci 2006;29:278-87.

11. Hasan NMY. The role of medium-chain fatty acids in the emulsification mechanistics of self-micro-emulsifying lipid formulations. Saudi Pharm J 2014;22:580-90.

12. Hasan NMY, Hayajneh FM, Khaleel MA, Alharthi SA, Shahada HM, Almalki HF. Development of potential self-micro emulsifying lipid formulation for the oral administration of curcumin. Int J Adv Pharm Biol Chem 2015;4 Suppl 3:590-602.

13. Sharma S, Khinchi MP, Sharma N, Agrawal D, Gupta MK Approaches to the development of solid-self micron emulsifying drug delivery system: formulation techniques and dosage forms-a review. Asian J Pharm Res Dev 2013;1 Suppl 5:146-56.

14. Hasan NMY. Preparation of solid self-micro-emulsified lipid systems for the delivery of hydrophobic drugs. Int J Phram Res 2015;7 Suppl 3:75-84.

15. Tang G, Cheng JG, Xu C. Development of solid self-emulsifying drug delivery systems: preparation techniques and dosage forms. Drug Discovery Today 2008;13 Suppl 13-14:606-12.

16. Balakrishnan P, Lee BJ, Oh DH, Kim JO, Hong MJ, Jee JP, et al. Enhanced oral bioavailability of dexibuprofen by a novel solid self-emulsifying drug delivery system (SEDDS). Eur J Pharm Biopharm 2009;72 Suppl 3:539-45.

17. Yi T, Wan J, Xu H, Yang X. A new solid self-micro emulsifying formulation prepared by spray-drying to improve the oral bioavailability of poorly water-soluble drugs. Eur J Pharm Biopharm 2008;70 Suppl 2:439-44.

18. Cerpnjak K, Zvonar A, Vrecer F, Gašperlin M. Development of a solid self micro emulsifying drug delivery system (SMEDDS) for solubility enhancement of naproxen. Drug Dev Ind Pharm 2015;41 Suppl 9:1548-57.

19. Liang LL, Yi T, Lam CWK. Effects of spray-drying and choice of solid carriers on concentrations of labrasol ${ }^{\circledR}$ and transcutol ${ }^{\circledR}$ in solid self-microemulsifying drug delivery systems (SMEDDS). Molecules 2013;18:545-60.

20. Bamba J, Cave G, Bensouda Y, Tchoreloff P, Puisieux F, Couarraze G. Cryoprotection of emulsions in freeze-drying: freezing process analysis. Drug Dev Ind Pharm 1995;21:1749-60.

21. Ito Y, Kusawake T, Rama PYV, Sugioka N, Shibata N, Kanji Takada K. Preparation and evaluation of solid oral heparin using emulsifier and adsorbent for in vitro and in vivo studies. Int J Pharm 2006;317 Suppl 2:114-9.

22. Ito Y, Kusawake T, Ishida M. Oral solid gentamicin preparation using emulsifier and adsorbent. J Controlled Release 2005;105:23-31.

23. Bhagwat DA, D'Souza JI. Formulation and evaluation of solid self-micro emulsifying drug delivery system using aerosil 200 as solid carrier. Int Curr Pharm J 2012;1 Suppl 12:414-9.

24. Raval C, Joshi N, Patel J, Upadhyay UMl. Enhanced oral bioavailability of olmesartan by using the solid self-emulsifying drug delivery system. Int J Adv Pharm 2012;2 Suppl 2:82-92.

25. Laddha P, Suthar V, Butani S. Development and optimization of self micro emulsifying drug delivery of domperidone. Braz J Pharm Sci 2014;50 Suppl 1:91-100.
26. Okimoto K, Miyake M, Ibuki R, Yasumura M, Ohnishi N, Nakai T. Dissolution mechanism and rate of solid dispersion particles of nilvadipine with hydroxypropylmethylcellulose. Int J Pharm 1997;159:85-93.

27. Abdalla A, Klein S, Mäder K. A new self-emulsifying drug delivery system (SEDDS) for poorly soluble drugs: characterization, dissolution, in vitro digestion and incorporation into solid pellets. Eur J Pharm Sci 2008;35 Suppl 5:457-64.

28. Setthacheewakul S, Mahattanadul S, Phadoongsombut N, Pichayakorn W, Wiwattanapatapee R. Development and evaluation of self-micro emulsifying liquid and pellet formulations of curcumin, and absorption studies in rats. Eur J Pharm Biopharm 2010;76 Suppl 3:475-85.

29. Chambin O, Jannin V, Champion D, Chevalier C, RochatGonthier MH, Pourcelot Y. Influence of cryogenic grinding on properties of a self-emulsifying formulation. Int J Pharm 2004;278 Suppl 1:79-89.

30. Kima W, Kwona MS, Yousafa AM, Balakrishnana P, Parka JH, Kima DS, et al. Comparison of a solid SMEDDS and solid dispersion for enhanced stability and bioavailability of clopidogrel napadisilate. Carbohydr Polym 2014;114:365-74.

31. Milovic M, Djuris J, Djekic L, Vasiljevic D, Ibric S. Characterization and evaluation of solid self-micro emulsifying drug delivery systems with porous carriers as systems for improved carbamazepine release. Int J Pharm 2012;436:58-65.

32. Zhao X, Zhou YQ, Potharaju S, Lou H, H Sun M, Brunson E, et al. Development of a self micro-emulsifying tablet of cyclosporineA by the liquisolid compact technique. Int J Pharma Sci Res 2011;2 Suppl 9:2299-308.

33. Cho W, Kim MS, Kim JS, Park J, Park HJ, Cha KH, et al. Optimized formulation of solid self-micro emulsifying sirolimus delivery systems. Int J Nanomed 2013;8:1673-82.

34. Kim M, Ha E, Choo G, Baek I. Preparation and in vivo evaluation of a dutasteride-loaded solid-supersaturatable self micro emulsifying drug delivery system. Int J Mol Sci 2015:16:10821-33.

35. Rosen $\mathrm{H}$, Abribat $\mathrm{T}$. The rise and rise of drug delivery. Nat Rev Drug Discovery 2005;4 Suppl 5:381-5.

36. Shen LJ, Wu FLL. Nanomedicines in renal transplant rejectionfocus on sirolimus. Int J Nanomed 2007;2 Suppl 1:25-32.

37. Hasan MYN. Self-micro-emulsifying lipid formulations to improve the bioavailability of poorly water-soluble drugs. $\mathrm{PhD}$ thesis, University of Bath; 2004.

38. Hasan NMY, Al-aram MSA, Al-wadie MSM, Althobaiti FAK, AlMalki MJA. Flavored self micro emulsifying lipid formulations for masking the organoleptic taste of pharmaceutical actives. J Appl Pharm Sci 2015;5 Suppl 11:127-34.

39. Gregory Thoorens G, Krier F, Leclercq B, Carlin B, Evrard B. Microcrystalline cellulose, a direct compression binder in quality by design environment-A review. Int $\mathrm{J}$ Pharm 2014;473:64-72.

40. Rubinstein MH. Tablets. In: Aulton ME, Aulton ME. Eds. Pharmaceutics: The Science of Dosage Form Design. Churchill Livingstone; 1988. p. 304-21.

41. Saigal N, Baboota S, Ahuja A, Ali J. Microcrystalline cellulose as a versatile excipient in drug research. J Young Pharm 2009;1:6-12.

42. Alderborn G, Nystrom C. Characterization of powder surface areas. In: Sandell E, Sandell E. (Eds.). Industrial Aspects of Pharmaceutics. Swedish Pharmaceutical Press; 1993. p. 146.

43. David Peters, John Denick Jr, Anil K Talwar. Magnesium trisilicate suitable for preparation of medicament adsorbates of antinauseants; 1987.

44. Sander C, Holm P. Porous magnesium alumino- metasilicate tablets as a carrier of a cyclosporine self-emulsifying formulation. AAPS PharmSciTech 2009;10 Suppl 4:1388-95.

\section{How to cite this article}

- Naser MY Hasan, Dhaifallah M Almalki, Mohammed JK Althuwaybi, Hassan M Alshehri. Smedds tablet: Compatibility of solid smedds using various pharmaceutical tablet excipients. Int J Pharm Pharm Sci 2016;8(9):246-251. 